\title{
Intracranial isolated varix mimicking a meningioma: the relevance of modern MRI techniques for reliable diagnosis
}

Variz intracraniana isolada mimetizando um meningioma: a relevância de técnicas modernas de RM para um diagnóstico confiável

Diogo Goulart CORREA $A^{1,2}$, Luiz Celso HYGINO DA CRUZJR.?

A 37-year-old man presented with headache. Brain vessel wall magnetic resonance imaging revealed a left temporal vascular ectasia with heterogeneous flow (Figure 1). Four-dimensional time-resolved magnetic resonance angiography (4DMRA) showed the lesion being progressively filled by contrast during the venous phase, with no arterial feeders (Figure 2 and Video).

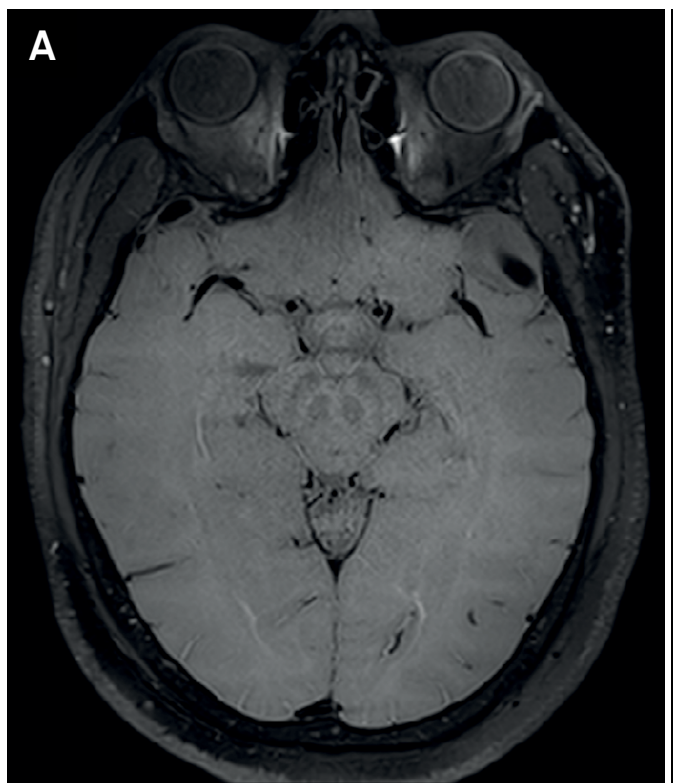

Isolated intracranial varix is a focal dilatation of a vein, without neural tissue or other vessels anomalies ${ }^{1}$. Its main differential diagnoses are meningioma and arteriovenous fistula ${ }^{2}$. Vessel wall imaging and 4DMRA can appropriately show the internal flow, absence of arterial components and progressive filling, during the venous phase, confirming the diagnosis and avoiding unnecessary surgery.

Figure 1. Isolated intracranial varix. Ectasia of a left temporal cortical venous vessel, well identified in the axial 3 -D T1 darkblood image, for intracranial vessel wall MRI, pre- (A) and postintravenous contrast injection (B), with heterogeneous filling by the contrast agent. Note the flow-void inside the lesion and its well-demarcated and smooth contours, marking the vascular nature of the lesion.

\footnotetext{
${ }^{1}$ Clínica de Diagnóstico por Imagem (CDPI), Rio de Janeiro RJ, Brasil.

${ }^{2}$ Universidade Federal do Rio de Janeiro, Hospital Universitário Clementino Fraga Filho, Departamento de Radiologia, Rio de Janeiro RJ, Brasil. Diogo Goulart Corrêa (iD) https://orcid.org/0000-0003-4902-0021; Luiz Celso Hygino da CruzJr iD) https://orcid.org/0000-0002-9771-5832 Correspondence: Diogo Goulart Corrêa; UFRJ; Rua Rodolpho Paulo Rocco 255, Cidade Universitária, Ilha do Fundão; $21941-913$ Rio de Janeiro RJ, Brasil; E-mail: diogogoulartcorrea@yahoo.com.br

Conflict of interest: There is no conflict of interest to declare.

Received 29 January 2019; Received in final form 30 March 2019; Accepted 19 May 2019.
} 

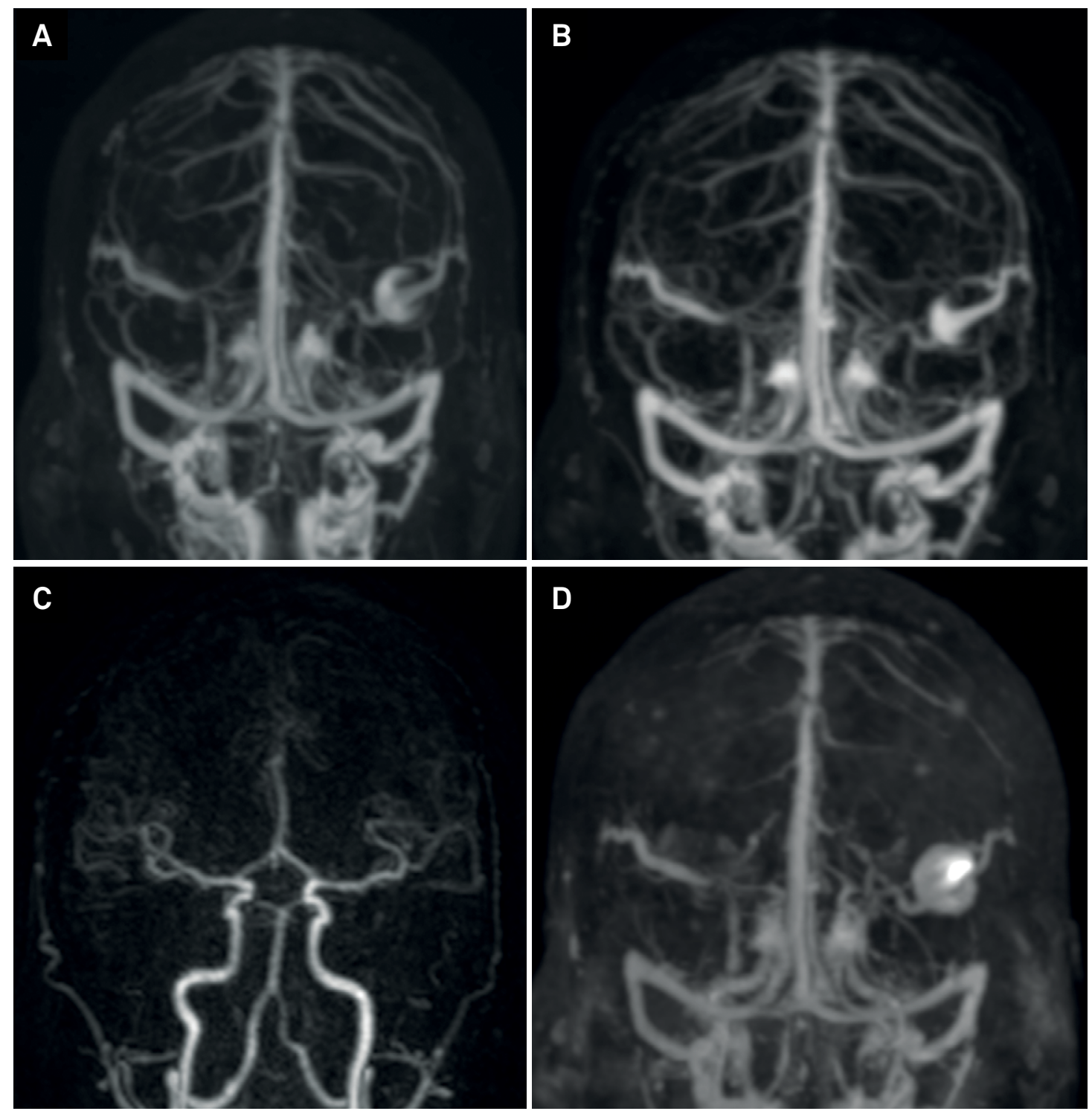

Figure 2. Isolated intracranial varix. 4D time-resolved MR angiography showed no arterial abnormalities (A) and progressive filling of the intracranial varix during the venous phase (B, C and D), with no arterial feeders or signs of arteriovenous malformation.

\section{References}

1. Hoell T, Hohaus C, Beier A, Holzhausen HJ, Meisel HJ. Cortical venous aneurysm isolated cerebral varix.

Interv Neuroradiol. 2004 Jun;10(2):161-5.

https://doi.org/10.1177/159101990401000210
2.

Tan ZG, Zhou Q, Cui Y, Yi L, Ouyang Y, Jiang Y. Extra-axial isolated cerebral varix misdiagnosed as convexity meningioma: a case report and review of literatures. Medicine (Baltimore). 2016 Jun;95(26):e4047. https://doi.org/10.1097/MD.0000000000004047 
In the manuscript "Intracranial isolated varix mimicking a meningioma: the relevance of modern MRI techniques for reliable diagnosis”, DOI: 10.1590/0004-282X20190125, published in the Arq Neuropsiquiatr 2020;78(2):124-5. Epub Jan 20, 2020, on page 125, Figure 2

Where it shows:
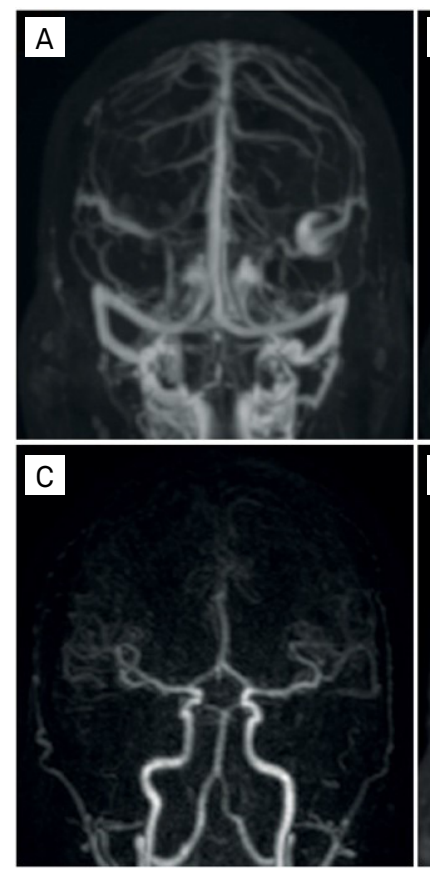

It should be:
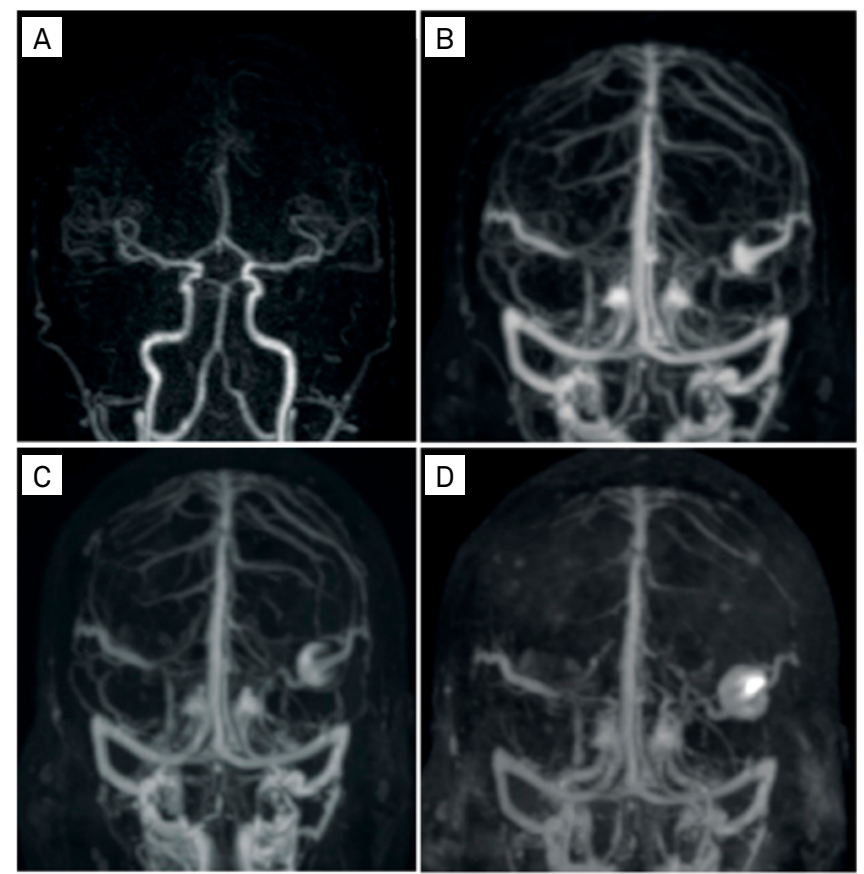